\title{
Lasers in Oral and Maxillofacial Surgery
}

\author{
Shravan Renapurkar and Robert A. Strauss
}

\subsection{Introduction}

The first successful demonstration of laser was performed by Maiman in 1960 who also predicted one of its uses to be in medical science $[1,2]$. Decades after the first medical use in the oral cavity and face, lasers are not just an adjunctive tool today but are an integral part of an Oral and Maxillofacial Surgeon's (OMS) armamentarium. Although $\mathrm{CO}_{2}$ laser has been the traditional workhorse for an OMS, advancement in the capabilities of $\mathrm{CO}_{2}$ lasers, as well as the development of other types of lasers, has helped grow their utility. Increasing use of lasers in turn has created greater evidence of its efficacy and safety record. Use of lasers has not only added advantages to conventional OMS procedures, as opposed to a scalpel, it has also given rise to newer procedures, which were not possible with conventional tissue-cutting tools.

\subsection{Laser Physics}

Modern lasers are simple to use but a lack of knowledge on the physics of lasers, inadequate training and caution in handling lasers, can give rise to potential adverse outcomes and unwanted complications. The term "laser" stands for light amplification by stimulated emission of radiation and was first used by Gordon Gould in 1957 [3]. The laser, as opposed to a regular light source, is composed of monochromatic, coherent and collimated beams, which, when they strike a suitable target, create photoacoustic, photochemical, photoablative, and photothermal effects. Laser light energy can undergo absorption, reflection, transmission, and scattering based on the optical properties of the target tissue or matter. For surgeons, the most desirable action is absorption into the

S. Renapurkar $(\bowtie) \cdot$ R. A. Strauss

Department of Oral and Maxillofacial Surgery, Virginia

Commonwealth University Medical Center, Richmond, VA, USA

e-mail: srenapurkar@vcu.edu; rastrauss@vcu.edu tissue, which creates the predictable photothermal outcome of coagulation and then vaporization of tissues [4].

The basic component of a laser unit includes a "laser cavity" where the laser beam is produced via the phenomenon of stimulated emission as postulated by Albert Einstein. The laser cavity is composed of an active medium, an excitation source acting as a pumping mechanism, and an optical resonator (Fig. 39.1). The active medium is the chemical (gas/ liquid/solid) that the type of laser is named after and is the material that undergoes stimulated emission. The photons of energy produced are collimated and amplified to produce the laser beam, which is then delivered to the target tissues via an appropriate delivery mechanism, either a flexible fiberoptic system, semiflexible hollow waveguides, or articulated mirrored arms (Fig. 39.2a-c). Lenses focus the active laser beam to create a "focal point," the point at which the energy is condensed to the smallest area to create the maximum effect. Some fiberoptic laser systems utilize a quartz or sapphire crystal at the tip of the fiber to enable the beam to be absorbed by this crystal and allow contact with tissues at the tip of the fiber, while others are used in a noncontact mode. A laser beam is an electromagnetic beam of radiation, which can fall anywhere in the spectrum of visible or invisible light. $\mathrm{Nd}$ :YAG, $\mathrm{CO}_{2}$, and erbium lasers fall into the infrared invisible spectrum; hence, they are often accompanied by a visible aiming beam, which helps the surgeon to know the point in the tissues where laser beam hits the target tissues. Aiming beams can be another low power laser or a regular light source [4] (Fig. 39.3).

The factors related to the use of lasers that are under control of the surgeon include the spot size, power, and time on target. The spot size of the laser is the width of the laser beam on target. At the focal point, the maximum energy is focused to produce the smallest spot size or the thinnest possible incision but to the greatest depth. When the tip of the laser delivery system is moved away from the tissues, the laser beam diverges causing a bigger spot size and the energy is then distributed over a larger area and the related depth is 
Fig. 39.1 Components of laser tube

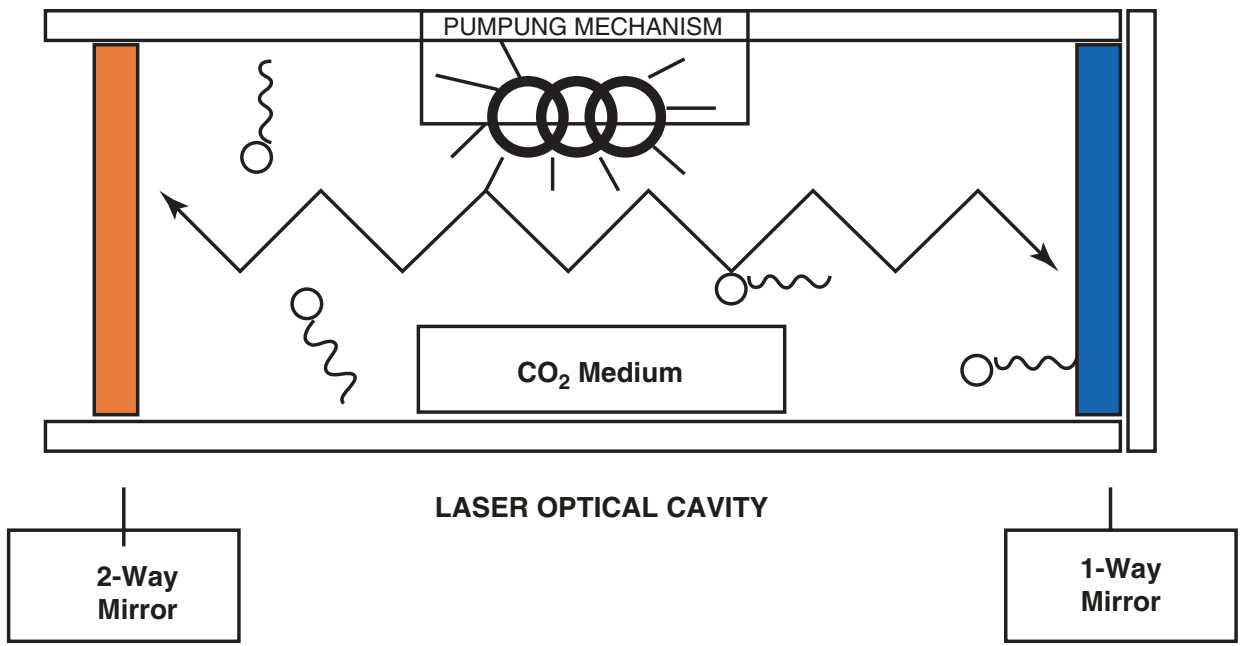

CAssociation of Oral and Maxillofacial Surgeons of India
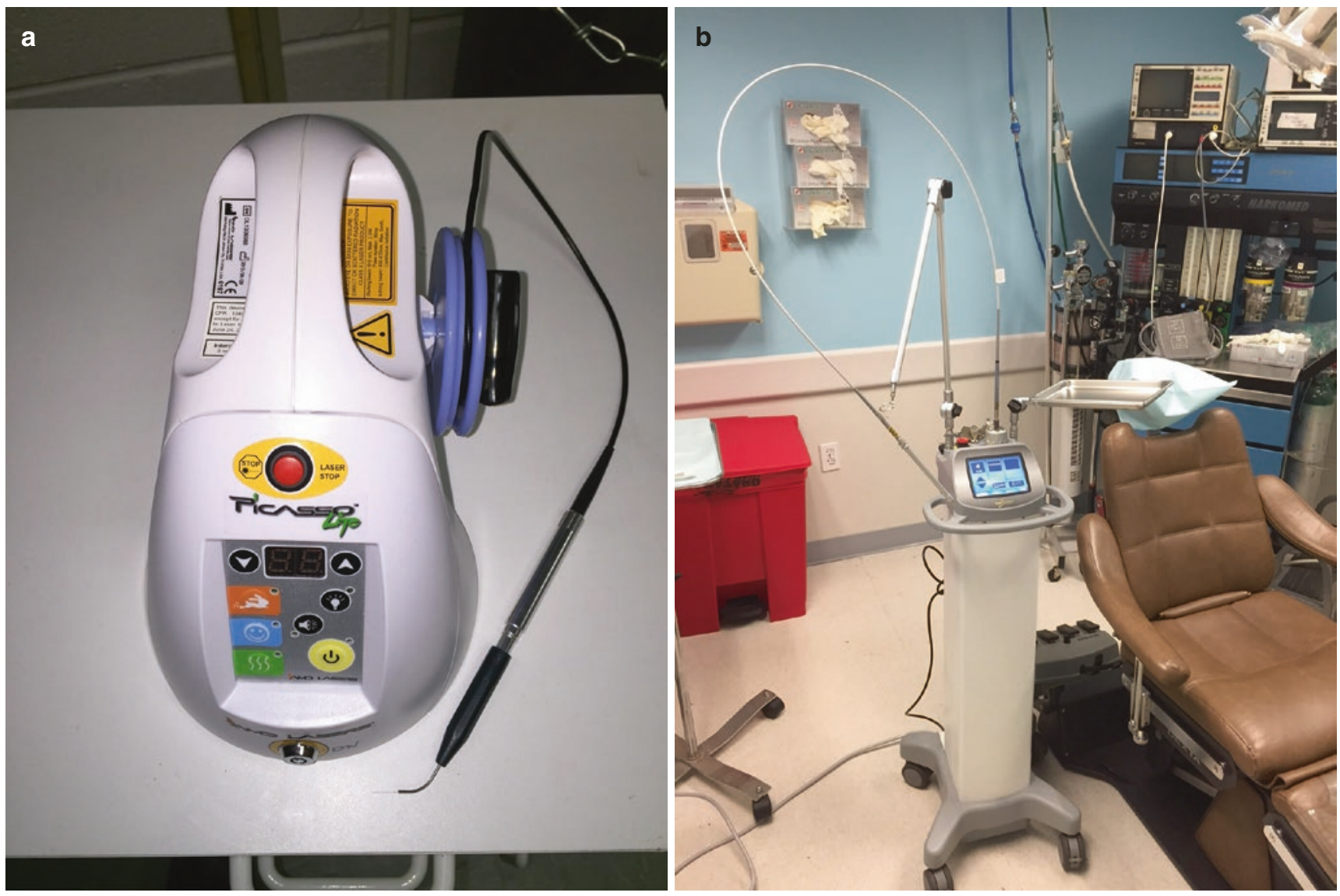

Fig. 39.2 (a) Fiberoptic laser. (b) Hollow waveguide laser. (c) Articulated arm laser 


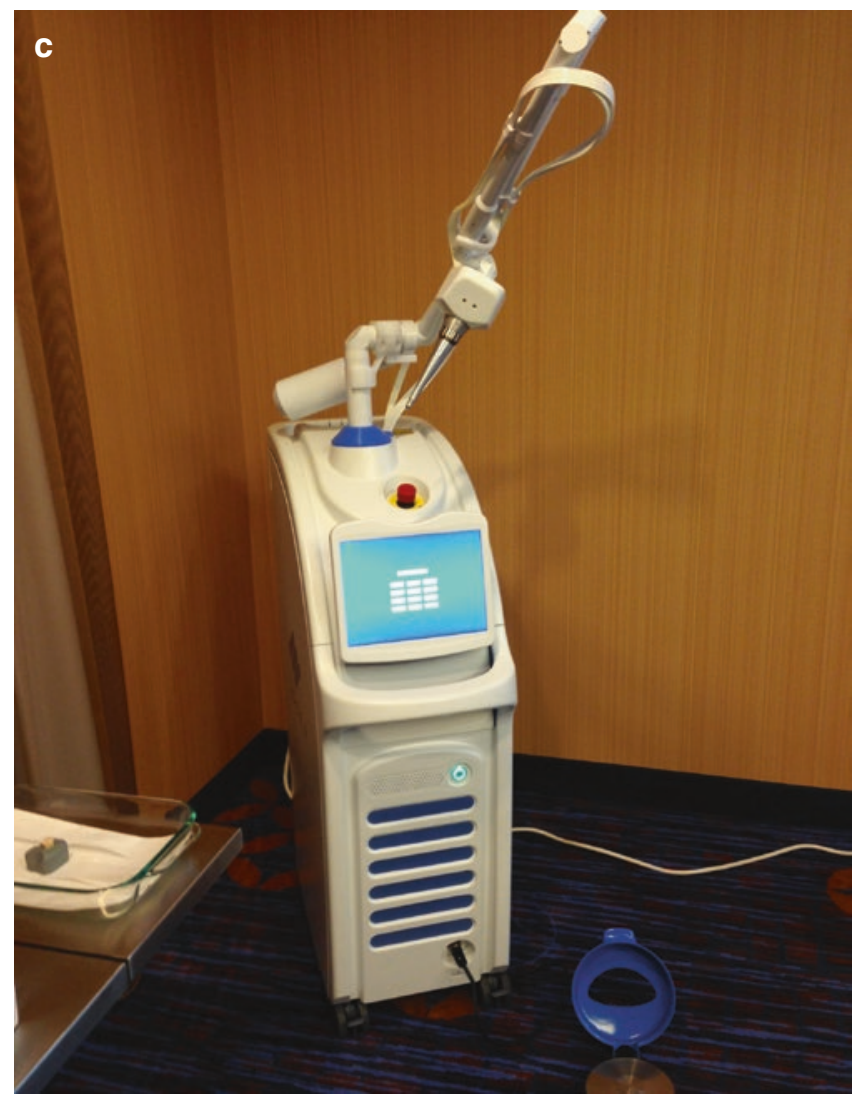

CAssociation of Oral and Maxillofacial Surgeons of India

Fig. 39.2 (continued)

decreased [5]. Laser emission modes and the surgeon's hand speed can affect the temperature rise and effect in the tissues. Lasers can be emitted in "continuous-wave" mode or in a "pulsed mode." Lasers used in pulsed mode allow time for tissues to cool before the next pulse of laser radiation is started while continuous wave mode of laser must be stopped manually to allow the tissues to cool. The time between pulses can help avoid thermal effects on surrounding tissues or excessive thermal effect on target tissues. The lasers with pulsed mode of emission can be of two types, "gated pulsed" or "true pulsed." True-pulsed lasers are pulsed by a mechanism within the laser cavity, while the gated-pulsed lasers have a shutter-like mechanism outside the laser cavity [4].

\subsubsection{Advantages of Laser}

Lasers have obvious advantages, which make them superior to conventional cutting tools. An ability to provide better hemostasis is a great advantage for surgeons to maintain visibility and reduce blood loss. Since spot size, power, and time on

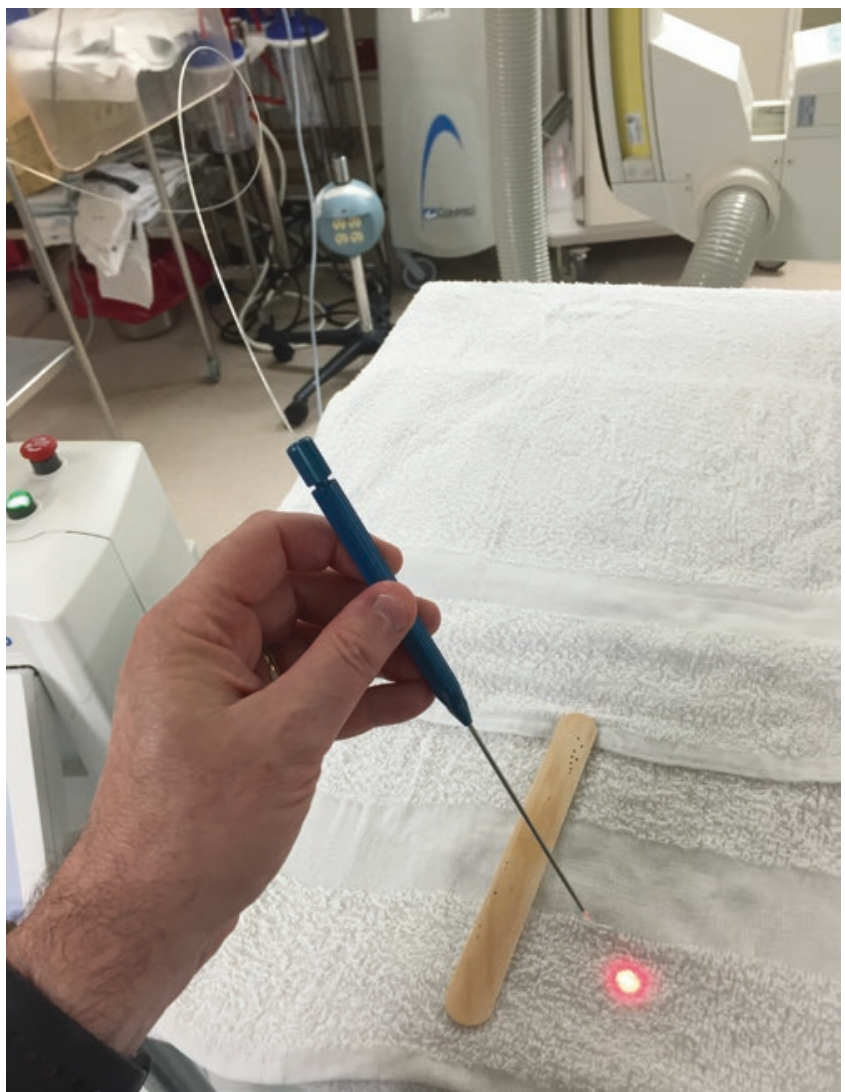

CAssociation of Oral and Maxillofacial Surgeons of India

Fig. 39.3 Low-level laser-aiming beam

target are regulated by the surgeon, lasers provide better control of desired tissue changes, which enhances the precision of surgery. Increased precision of the depth of tissue damage along with fewer myofibroblasts in laser wounds compared to scalpel wounds, allow for improved tissue healing and decreased scarring. The mentioned advantages are presumed to decrease postoperative pain with the use of lasers, although the pathophysiology for this effect is not well understood.

\subsubsection{Disadvantages of Laser}

Despite several advantages of lasers in surgery, the provider should make sure the benefits outweigh the risks and disadvantages. Hard-tissue lasers such as Er:YAG and Er:CR:YSGG do not match the speed of bone or tooth cutting as do conventional tools such as burs or saws. Soft-tissue healing after laser-assisted incision or excision is slower (although with decreased scarring) than tissue healing using scalpels. The associated learning curve and costs of the laser equipment add to the drawbacks of using lasers. 


\subsection{Selection of Lasers}

The type of laser to be used is based on the laser's physical characteristics, interaction with the target tissues, and the goals of the procedure. For example, $\mathrm{CO}_{2}$ laser's excellent affinity for water, which is the main component of soft tissues, makes it the most widely used laser for soft-tissue surgical applications. The most commonly used $\mathrm{CO}_{2}$ laser is the 10,600-nm wavelength, although 9600-nm and other wavelength variants of this laser exist. The $\mathrm{CO}_{2}$ laser is currently the most ideal laser used for most intraoral and extraoral soft-tissue procedures. The absorbed energy causes vaporization of the intracellular fluid causing tissue vaporization, while lateral heat conduction causes contraction of collagen and closure of blood vessels of approximately $500 \mu$ or less in diameter. High-power $\mathrm{CO}_{2}$ lasers are generally delivered via articulating arms, but new hollow waveguide systems suitable for office use provide increased accessibility intraorally along with their ease of use [6, 7].

Other lasers include the Nd:YAG (a crystal of Ytrrium, Aluminum, and Garnet doped with the rare earth element Neodymium) laser, which functions in the near-infrared electromagnetic spectrum at $1064 \mathrm{~nm}$, and has minimal water and superficial tissue absorption leading to deeper tissue penetration. Hence, the Nd:YAG can be used for coagulation of deeper and larger (2-3 mm) diameter vessels. These qualities of $\mathrm{Nd}$ :YAG have led to its use in treating angiomatous or vascular tissue lesions, although this same lack of water absorption limits its utility for the OMS. Depending on the desired effect, the Nd:YAG laser can be used both in contact and noncontact modes [8-10].

The Er:YAG laser works at a 2940-nm wavelength and is even more highly absorbed in water than the $\mathrm{CO}_{2}$ laser leading to rapid absorption by the superficial layers of tissue and minimal penetration. This can be an advantage in some cases but also means that this laser is less effective on tissue than the $\mathrm{CO}_{2}$ laser. As an example, when used for cosmetic skin resurfacing it shows much more superficial effects, which heal quite quickly, but also shows much less of a result than $\mathrm{CO}_{2}$ laser does. For this reason, it has fallen somewhat out of favor for this purpose [11-15]. Owing to limitation of its thermal effects mostly in superficial layers of soft and hard tissue, Er:YAG laser has become popular in implant dentistry. It can be used on both soft and hard tissues and finds its application in bone preparation, second-stage surgery, treatment of peri-implantitis. Being reflected off the surface, it has minimal or no apparent adverse effects on dental implants [16].

The Holmium:YAG laser is generated at a 2100-nm wavelength, which enables it to be delivered in contact mode via fiberoptic cable also demonstrates very little water absorption but is well absorbed by other tissue components [17]. This allows it to be transmitted through water-rich environments while having similar tissue effects as the $\mathrm{CO}_{2}$. Minimal lateral thermal damage, precise depth of cut, and good coag-

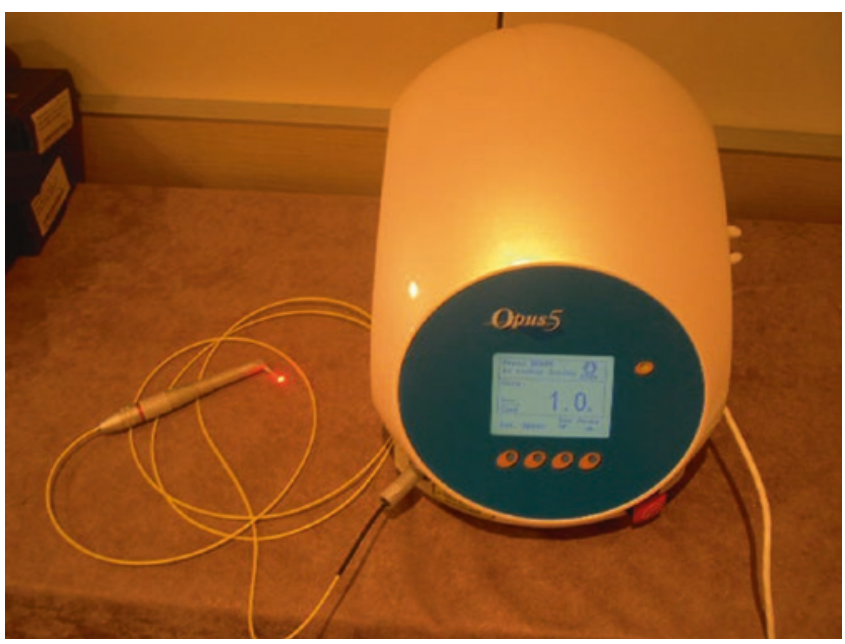

CAssociation of Oral and Maxillofacial Surgeons of India

Fig. 39.4 Diode laser

ulation combined with its ability to be used in presence of saline/lactated Ringer's solution makes it the preferred laser for operative TMJ arthroscopy [18].

Diode lasers at wavelengths between 805 and $980 \mathrm{~nm}$ have been reported to be compact, inexpensive, and easy to use in OMS procedures (Fig. 39.4). These can be used in continuous or pulse modes with contact or noncontact handpieces. However, it should be understood that these wavelengths are not well absorbed by soft tissues (although pigmented tissue will absorb it the most), the use of this laser wavelength would lead to very limited effects on surface tissue and very deep, poorly controlled, and undesirable tissue penetration. This is bypassed by using a material on the tip of the fiber that absorbs these wavelengths (either pigmented material such as ink paper or a suitable crystal material) and creates a red hot thermal tip, which is then used in surgery. In reality, the laser wavelength produced is not actually used for surgery; it is only absorbed by the fiber tip to essentially produce a thermal cautery. Although diodes are cheap and easy to use due to their fiberoptic contact tip, this thermal cautery effect rather than the use of the actual laser beam is very inefficient for surgery and severely limits its use by the OMS [19].

\subsection{Applications of Lasers in Oral and Maxillofacial Surgery}

Three basic categories of application of lasers in OMS can be classified as follows:

1. Incisional/excisional procedures

2. Vaporization (tissue ablation)-based procedures

3. Surgical hemostasis 


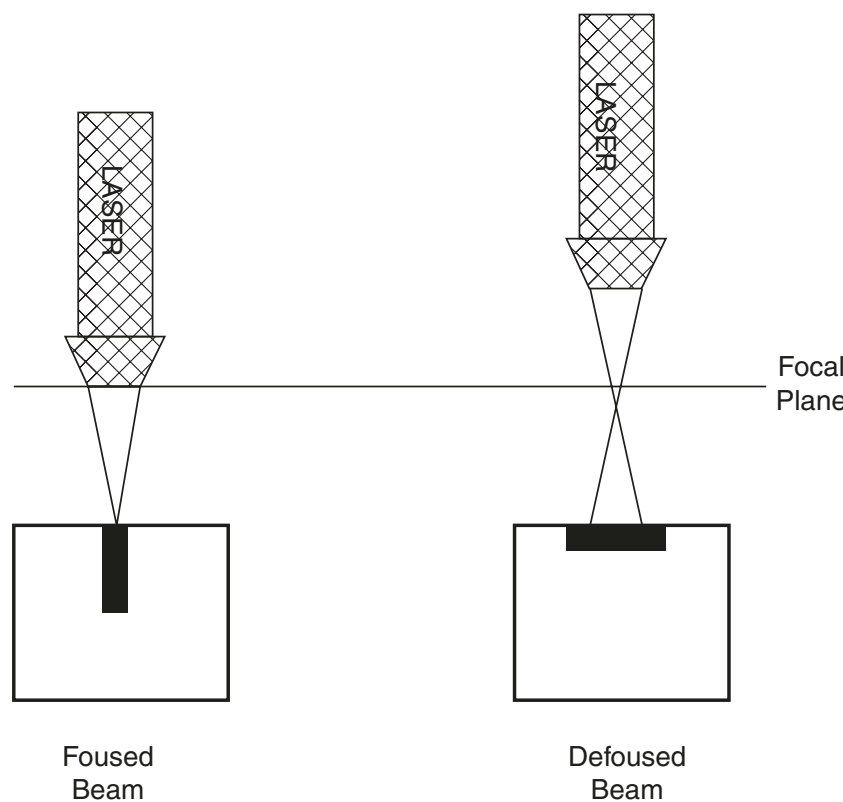

CAssociation of Oral and Maxillofacial Surgeons of India

Fig. 39.5 Focused vs. defocused beam

Incisional procedures require a precise thin cut with careful control of the depth of the cut. The thickness or thinness of the cut with a laser is controlled by the spot size (usually $0.1-0.4 \mathrm{~mm}$ ). The laser beam's focal length is usually between $1 \mathrm{~mm}$ and $1 \mathrm{~cm}$, depending on the delivery system, and is where the smallest spot size can be achieved with maximum power density. This is called "focused mode" (Fig. 39.5). The laser can be controlled by a foot pedal, but it is often useful to limit time on tissue to speeds faster than a foot control allows. Hence, a "gated/pulsed mode" can be used to generate 2-20 pulses per second to create or mark a dotted outline with lesser depth and allow careful delineation of the margins of the excision. This is then followed by a continuous mode (using the foot pedal) to "connect the dots" and complete the excision. The settings to obtain a desired depth of cut vary from one tissue to another due their different water content and absorption coupled with the surgeoncontrolled factors as mentioned earlier. It is not possible to have standard laser parameters for all types of tissues or lesions. The smallest spot size possible with 4-10 W power can be a good initial setting. The initial cut then gives the surgeon ability to observe the clinical effect and depth of incision, which then can be used to lead to adjustments of the power and time on target to achieve the desired changes. Common soft-tissue lesions that can be incised or excised using lasers include fibromas, mucoceles, epulis fissuratum, mucosal or gingival lesions, papillomas, etc. Wound closure after a laser-assisted incisional biopsy or excisional procedure is often unnecessary due to the limited scarring and excellent hemostasis and is up to the surgeon's discretion, as healing is excellent regardless of closure. Closure does not usually effect hemostasis or pain relief (Fig. 39.6a-c) [5].
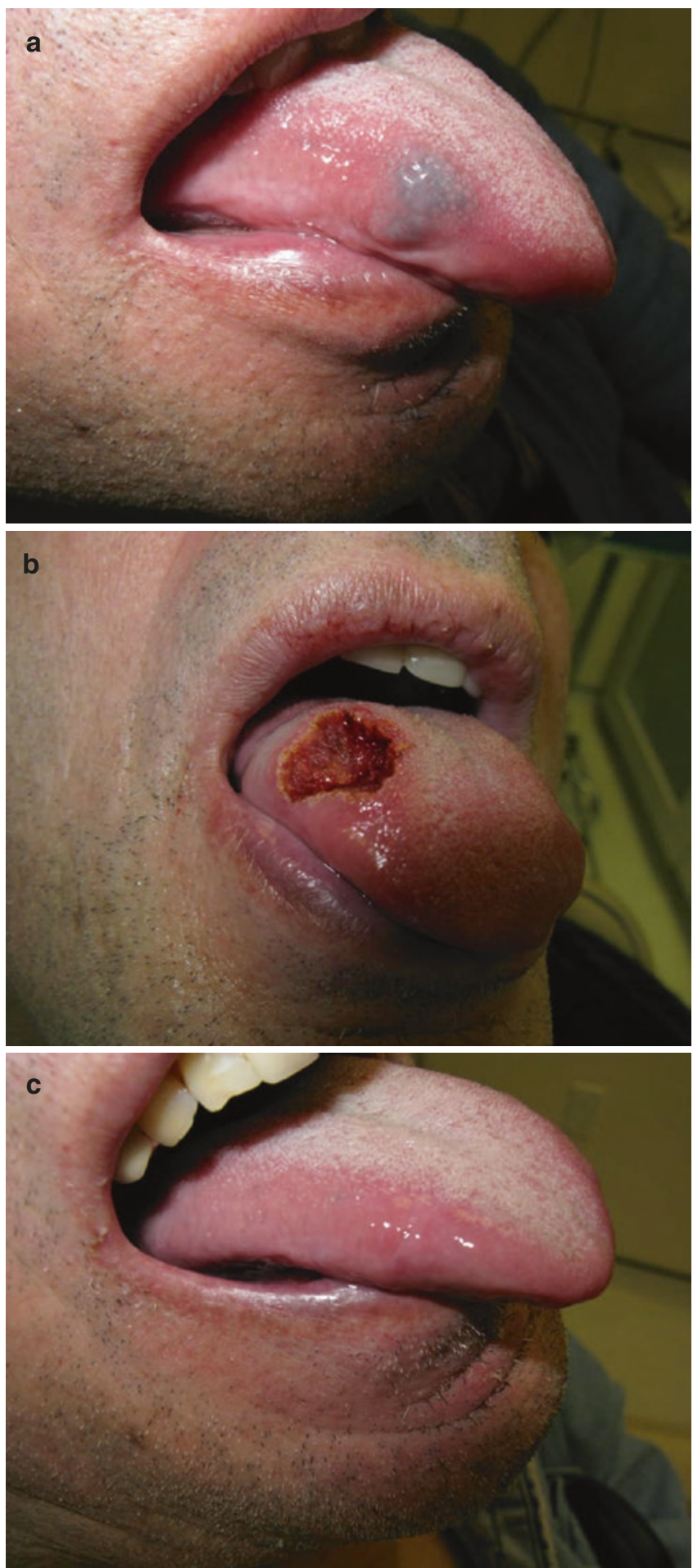

CAssociation of Oral and Maxillofacial Surgeons of India

Fig.39.6 (a) Lesion of tongue. (b) Tongue after laser excision with no closure. (c) Excellent healing

Ablative or vaporization procedures are done when the surgeon wants to remove only a superficial layer of the tissue. Lasers, cryotherapy, chemical peeling, and scalpel can be used for this purpose, but the precision of cut and control of the depth of tissue changes along with excellent hemo- 
stasis make lasers the preferred tool for vaporization procedures. Lasers, when used for vaporization procedures, are used defocused so as to decrease the power density (the energy per unit area) and limit the depth of effect while increasing the area of the tissue ablation. The spot size used for vaporization ranges from 1.5 to $3 \mathrm{~mm}$ and allows large surface areas to be removed very superficially (literally cell layers at a time if desired). This is ideal for large but flat and superficial lesions such as hyperkeratosis, dysplasia, lichen planus, etc. The laser is again used in gated mode to carefully and precisely outline the margins. This is followed by passing the laser in overlapping "U"-shaped patterns to cover the entire area. The parameters can be adjusted by the surgeon, just as in incision cases, after the first pass is done at $4-10 \mathrm{~W}$ power. As implied by vaporization, there is no tissue available for biopsy in these cases. Hence, a definitive diagnosis should be established prior to performing ablative or vaporization procedures on mucosal lesions (Fig. 39.7a-c).

Due to the ability of $\mathrm{CO}_{2}$ lasers to constrict blood vessels rather than coagulate blood, it can be an excellent tool to obtain hemostasis in most surgical wounds where the vessels are smaller than the thermal effect of the laser in tissue (about $500 \mu$ ). The lateral thermal effect of the laser beam should be equal to or greater than the diameter of the bleeding vessels. If the vessel is of larger diameter, conventional hemostatic techniques should be used. For small superficial vascular lesions, the $\mathrm{CO}_{2}$ laser can be used to excise the lesion (since the feeding vessels are usually smaller than $500 \mu$ ), while deeper or larger vascular lesions are best treated using lasers that are specifically absorbed by hemoglobin, leading to true coagulation of the lesion itself [6].

\subsection{Specific Examples of Application of Lasers in Oral and Maxillofacial Surgery}

\section{Cosmetic facial surgery:}

The use of lasers in cosmetic surgery has changed these procedures significantly over the years. The advantages of lasers as previously described, including the capability of lasers to only affect the superficial layers of skin with precise depth control, turned out to be its critical advantage. Lasers in cosmetic facial surgery can be used both for incisional or ablation procedures based on indication [20].

Lasers used for laser skin resurfacing (removal of superficial skin wrinkles from the face) are an example of ablation or vaporization procedure. In skin resurfacing procedures, the superficial layers of the epidermis and
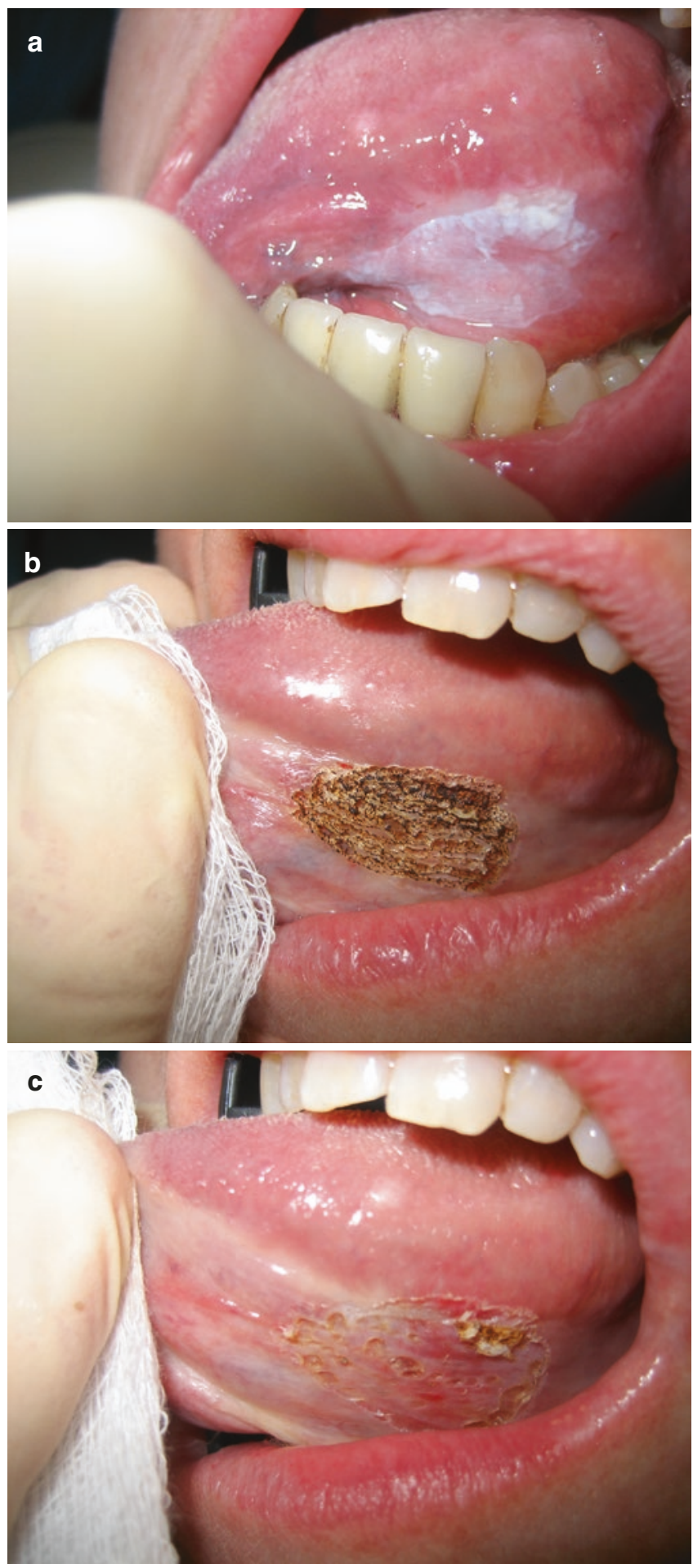

CAssociation of Oral and Maxillofacial Surgeons of India

Fig. 39.7 (a) Hyperkeratosis of lateral tongue. (b) Laser ablation of tongue. (c) Healing after laser ablation

papillary dermis are removed while leaving behind the reticular layer of the dermis with its adnexal structures. This layer, if intact, provides epithelial cells that are required for rapid re-epithelialization of skin in a uniform 


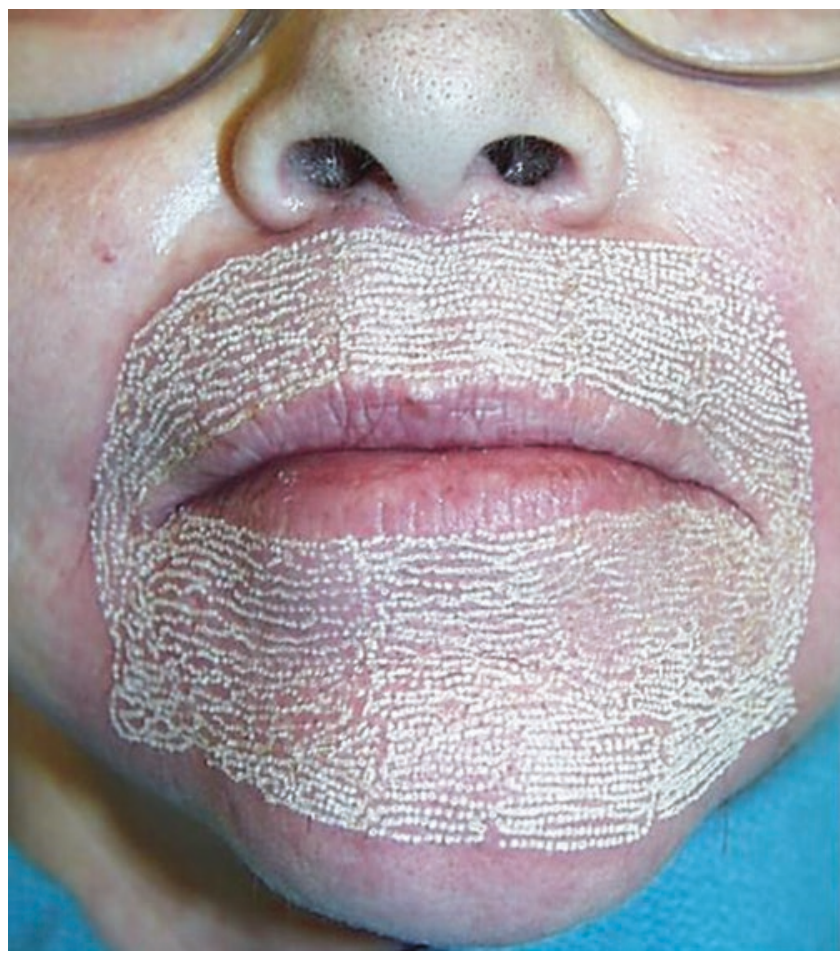

CAssociation of Oral and Maxillofacial Surgeons of India

Fig. 39.8 Laser cosmetic skin resurfacing of face

manner. As opposed to chemical peels or dermabrasion, lasers offer more precise depth control, which is crucial in uniform healing and improved outcomes. $\mathrm{CO}_{2}$ and the Er:YAG are the commonly used lasers for skin resurfacing, although recent improvements in the way $\mathrm{CO}_{2}$ is used to improve results with lessened postoperative healing time, have severely diminished the use of the Er:YAG. Although the $\mathrm{CO}_{2}$ laser is most commonly used and is more effective, it can be associated with long-term erythema and greater risk of scarring if exposure is done too deeply. Since $\mathrm{CO}_{2}$ is a continuous-wave beam, which means that even at a short "pulse" the laser would be on tissue too long and lead to scarring, it must be electronically "pseudopulsed" at high powers to obtain the short times needed to reduce risk from lateral thermal damage to the unintended underlying dermis (roughly less than $1000 \mu$ s). On the contrary, the Er:YAG laser has less penetration in skin owing to its higher affinity to water in tissue. It is also a true pulsed laser and hence it allows higher power with shorter pulse duration. Although this is an advantage of Er:YAG laser, which helps reduce risk of excessive ablation and scarring, as mentioned before, it also decreases the effectiveness and results of the Er:YAG laser and most surgeons have abandoned its use in favor of newer $\mathrm{CO}_{2}$ lasers that create very deep but thin vertical columns in the skin, allowing for tissue contraction with quick healing and less chance of scarring [21].
In skin resurfacing, as opposed to ablation of intraoral mucosal pathology, the passes of laser should not be overlapping to avoid excessive tissue ablation (Fig. 39.8). Computer pattern generator handpieces $(\mathrm{CPG})$ can be used, which automatically create a uniform pattern of coverage on the skin (Fig. 39.9a, b) [22].

Skin resurfacing principles are also used in scar revision procedures. The prominence or visibility of a scar is mainly affected by the surface depression or elevation. The $\mathrm{CO}_{2}$ and Er:YAG lasers can be used to reduce the elevation of the scar tissue or decrease the elevation of the surrounding skin to make a depressed scar tissue blend well with it (Fig. 39.10a-c). Healing scars can also have hypervascularity as evidence by prolonged erythema. This can be managed by decreasing the vascularity within the scar by use of vascular-specific lasers such as $532-\mathrm{nm}$ KTP:YAG or Pulsed Dye Lasers (PDL) lasers [23].

In blepharoplasty, the $\mathrm{CO}_{2}$ laser can be used to make a transconjunctival incision on the lower eyelid as well as the skin incision for the upper eyelid blepharoplasty. The use of laser to then excise muscle or fat with excellent hemostasis provides great visualization and tissue control (Fig. 39.11).

In endoscopic brow lift techniques, lasers are passed through either flexible fiberoptic cables or through small diameter hollow waveguide extensions in order to be used for incisions made within the optic cavity. The advantage of using lasers in endoscopic procedures is to provide precise incisions with excellent hemostasis, which aids in better visualization. Laser is used to incise the periosteum and/or muscle attachments. $\mathrm{CO}_{2}$ laser is a commonly used laser for this purpose.

\section{Intraoral mucosal surgery:}

Lasers have been extensively used in intraoral mucosal surgeries. Common applications include incisional/excisional biopsy of intraoral soft-tissue lesions (Fig. 39.12ac), frenectomy (Fig. 39.13a, b), ablation of premalignant lesions, preprosthetic procedures such as vestibuloplasty and excision of epulis fissuratum (Fig. 39.14a-d). As mentioned previously in this chapter, advantages of lasers stand superior compared to traditional scalpels in terms of wound healing, tissue handling, and hemostasis, which ultimately help improve patient experience when used for intraoral procedures as well. Vaporization or ablation of tissues intraorally is usually performed on premalignant lesions, commonly for white lesions such as hyperkeratosis or mild epithelial dysplasia. More severe dysplasias are best excised with the laser to allow for margin control. Definitive diagnosis with the help of a biopsy is a precursor for management of premalignant lesions with laser vaporization since there will be no specimen to biopsy [24].

Although diode, ND:YAG, Er:YAG and $\mathrm{CO}_{2}$ lasers can be used for intraoral mucosal surgeries $\mathrm{CO}_{2}$ lasers stand out as the workhorse and most studied laser over the 

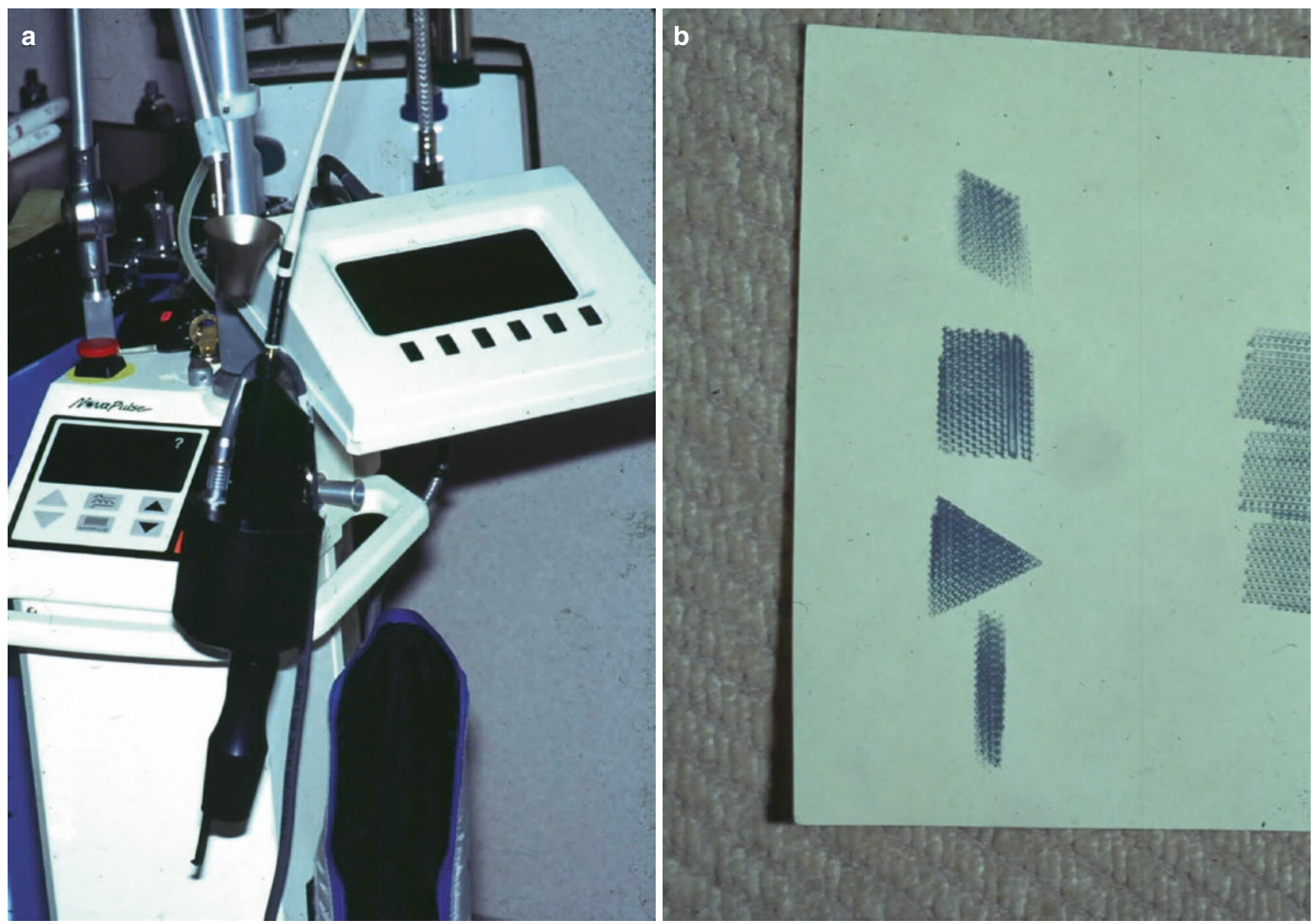

CAssociation of Oral and Maxillofacial Surgeons of India

Fig. 39.9 (a) Computerized pattern generator (CPG) for laser skin resurfacing. (b) Optional patterns for CPG

past four decades. When using lasers intraorally on intended soft tissues, care must be exercised to protect adjacent hard/soft tissue from inadvertent damage or devitalization due to pulpal damage. This is done with either a moist gauze, a mouth guard, a wet tongue blade, or nonreflective plastic instrumentation [25]. The use of lasers as compared to scalpel is presumed to also provide a decreased chance for lymphatic and hematogenous seeding as an added advantage in the management of premalignant or malignant lesions. Principles and technique of incision and ablation have been detailed elsewhere in the chapter.

\section{Implant surgery:}

Lasers are also useful in the management of periimplant soft tissues. 10,600-nm wavelength $\mathrm{CO}_{2}$ laser and 980-nm diode are the commonly used soft-tissue lasers in implant surgery. ND:YAG laser, due to its inherent high depth of penetration and risk for damage to adjacent tissue and implant surface, is considered unsafe for use on implants. Er:YAG laser, which has been approved for use on hard tissues, has been used in uncovering a thin layer of bone in second-stage implant uncovering and initiating the implant osteotomy, but there is need for further data on the use of Er:YAG for complete preparation of implant osteotomy. 9300-nm $\mathrm{CO}_{2}$ laser has been used for hardtissue applications, but more data on its safety and efficacy are needed. Advantages of using lasers in implant surgery include the precision, atraumatic tissue handling, bloodless field of view, and decreased bacterial contamination. Lasers have been used for several indications in implant surgery, including implant site preparation procedures such as the release of frenal attachment, excision of redundant tissue, and incision placement prior to bony osteotomy. Placement of incisions with lasers as opposed to scalpel creates less inflammation, swelling, and postoperative discomfort to the patient as well as added property of tissue sterilization from antibacterial effect. They can also be used for second-stage surgery, including removal of soft tissue and, in the case of Erbium lasers and $9300 \mathrm{~nm} \mathrm{CO}$ lasers, bone covering the implant [26]. 

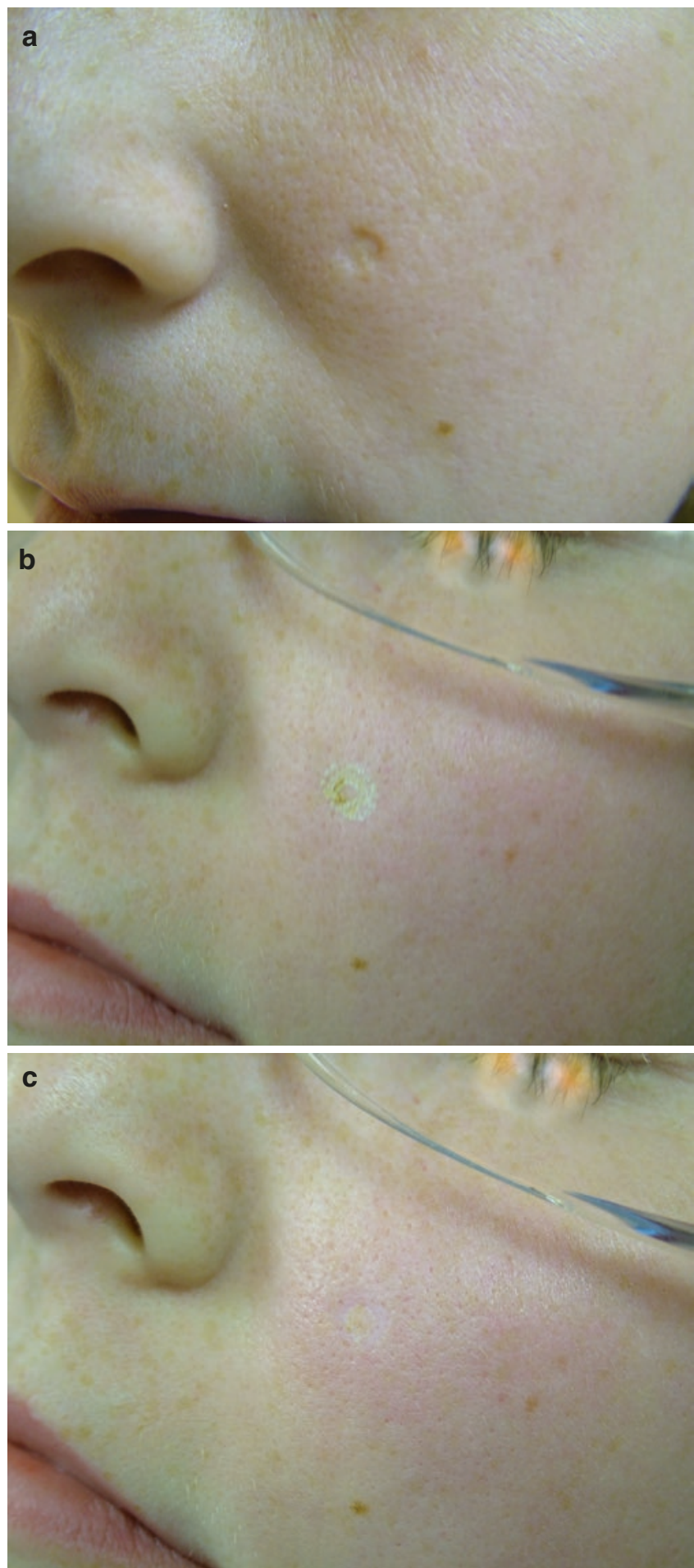

CAssociation of Oral and Maxillofacial Surgeons of India

Fig. 39.10 (a) Depressed scar of face. (b) Blending of scar using $\mathrm{CO}_{2}$ laser. (c) Results of laser scar revision

Treatment of mucositis and peri-implantitis around implants is a challenging problem in implant surgery with limited efficacy when managed via conventional treatment protocols. If an implant with signs of peri-implanti-

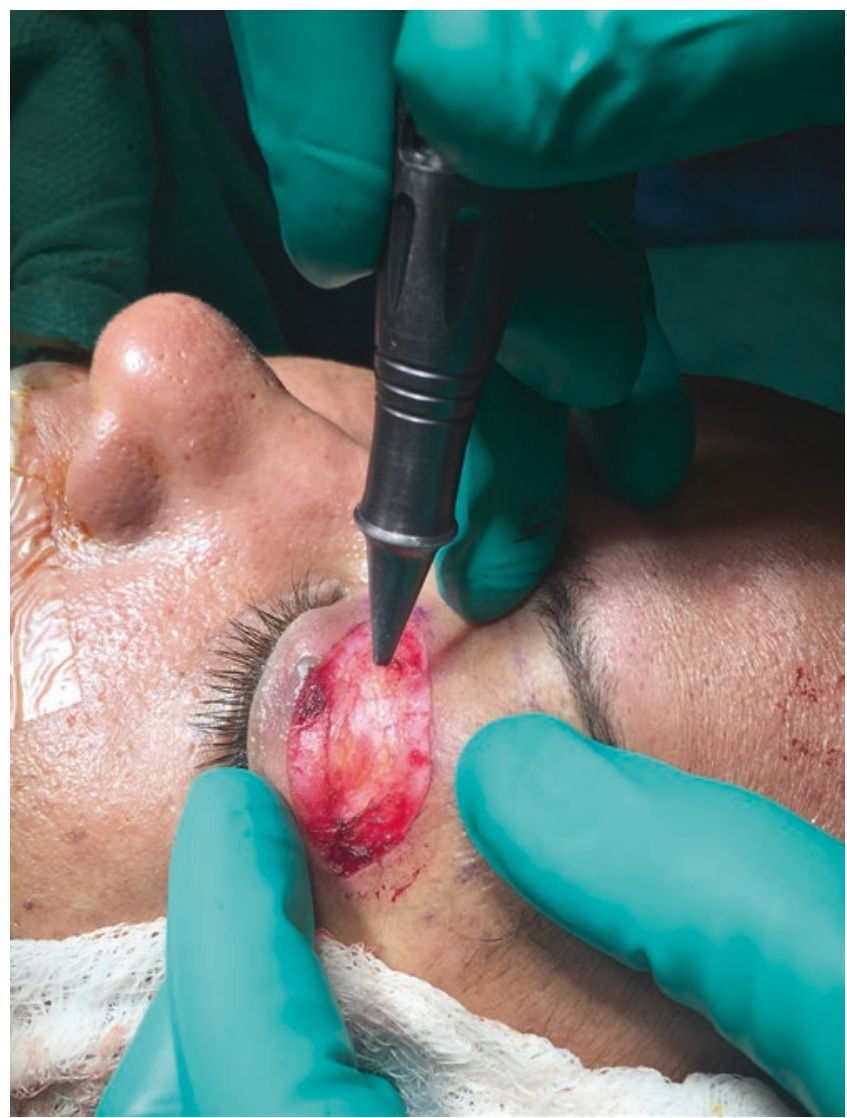

CAssociation of Oral and Maxillofacial Surgeons of India

Fig. 39.11 Laser blepharoplasty

tis is deemed stable without severe bone loss and/or mobility, then treatment is attempted to salvage. Treatment of choice includes debridement of the granulation tissue accompanied by the administration of antibiotics around the implant for the eradication of as much bacteria as possible followed by bone graft of any defect created. Traditional tools include plastic instruments, citric acid, chlorhexidine, and topical Tetracycline. A laser-assisted algorithm for management of peri-implantitis includes obtaining access to the implant in question via a laser incision and reflection of flap leading to exposure of implant and surrounding bone. Then, the pathologic tissue is vaporized by laser energy and the implant surface and bony defect are decontaminated by the laser, which is accomplished by ablating the surface at low energies to kill off any bacteria on the surface as well as any attached soft tissue. Bone grafting, if necessary, can then be performed. Data have shown significantly better outcomes in cases of peri-implantitis as compared to conventional tools. As in other laser-assisted surgeries, healing is enhanced because of reduced inflammation and decreased postoperative pain as opposed to conventional tools [26] (Fig. 39.15a, b). 

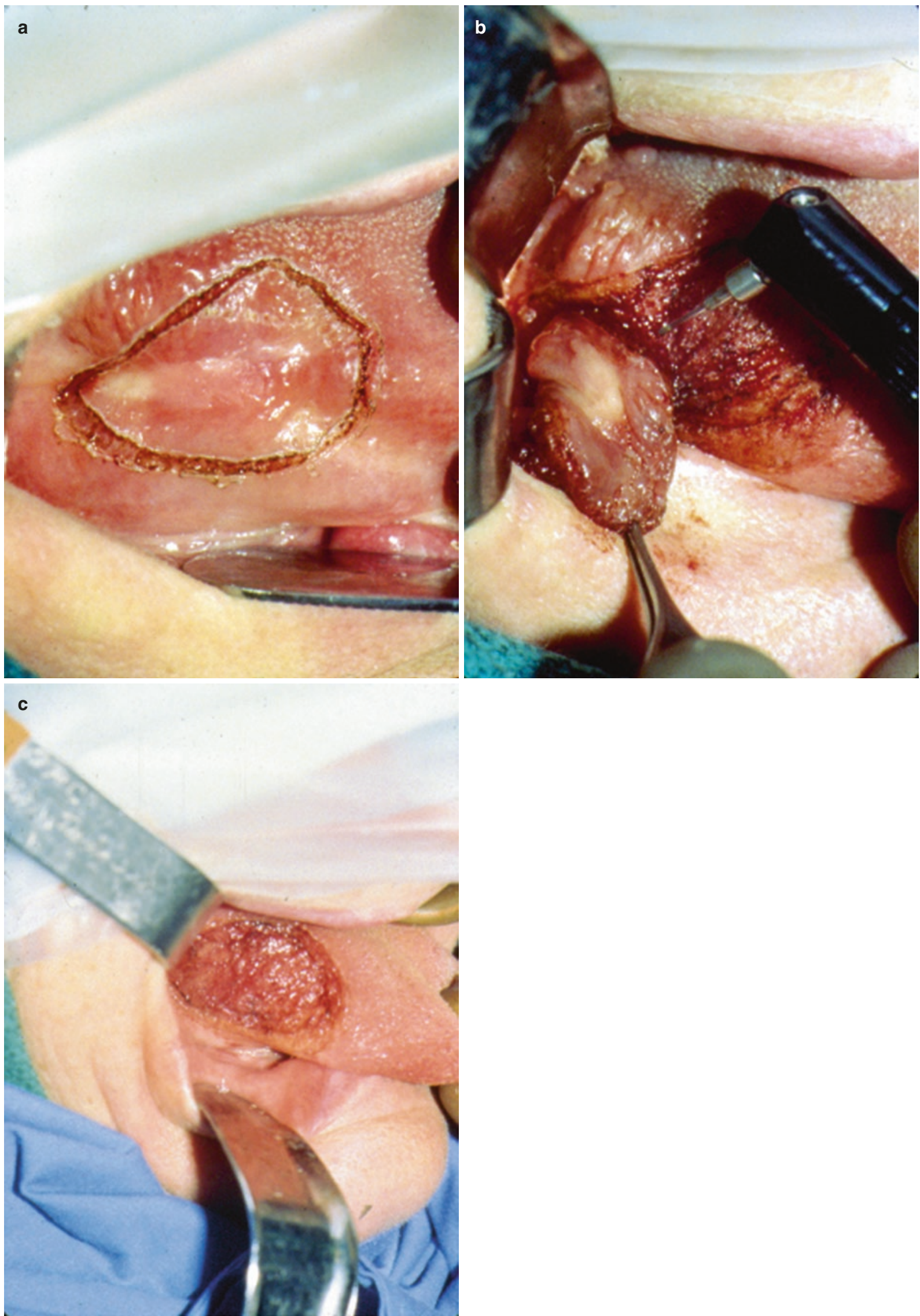

CAssociation of Oral and Maxillofacial Surgeons of India

Fig. 39.12 (a) Outlining a small tongue cancer for laser excision. (b) Excision of lesion with $\mathrm{CO}_{2}$ laser. (c) Lesion excised and allowed to heal with no closure 

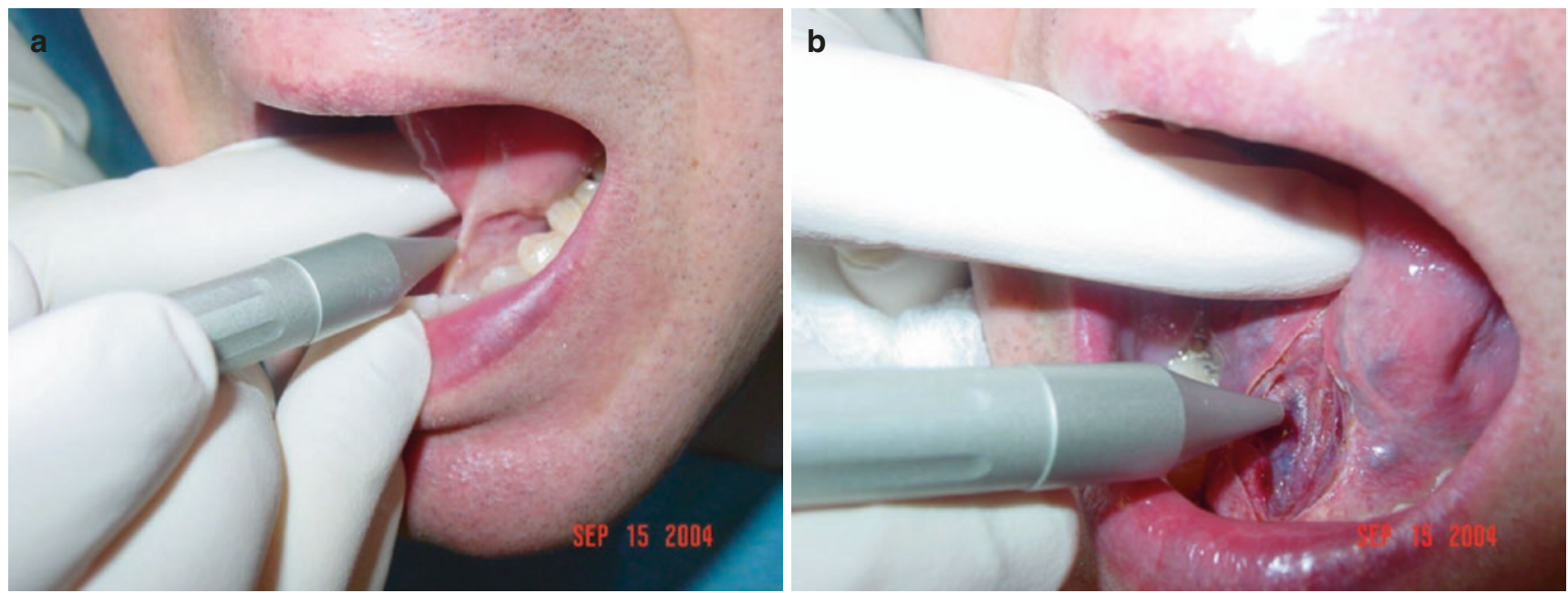

CAssociation of Oral and Maxillofacial Surgeons of India

Fig. 39.13 (a) Laser frenectomy with $\mathrm{CO}_{2}$ laser. (b) After laser frenectomy
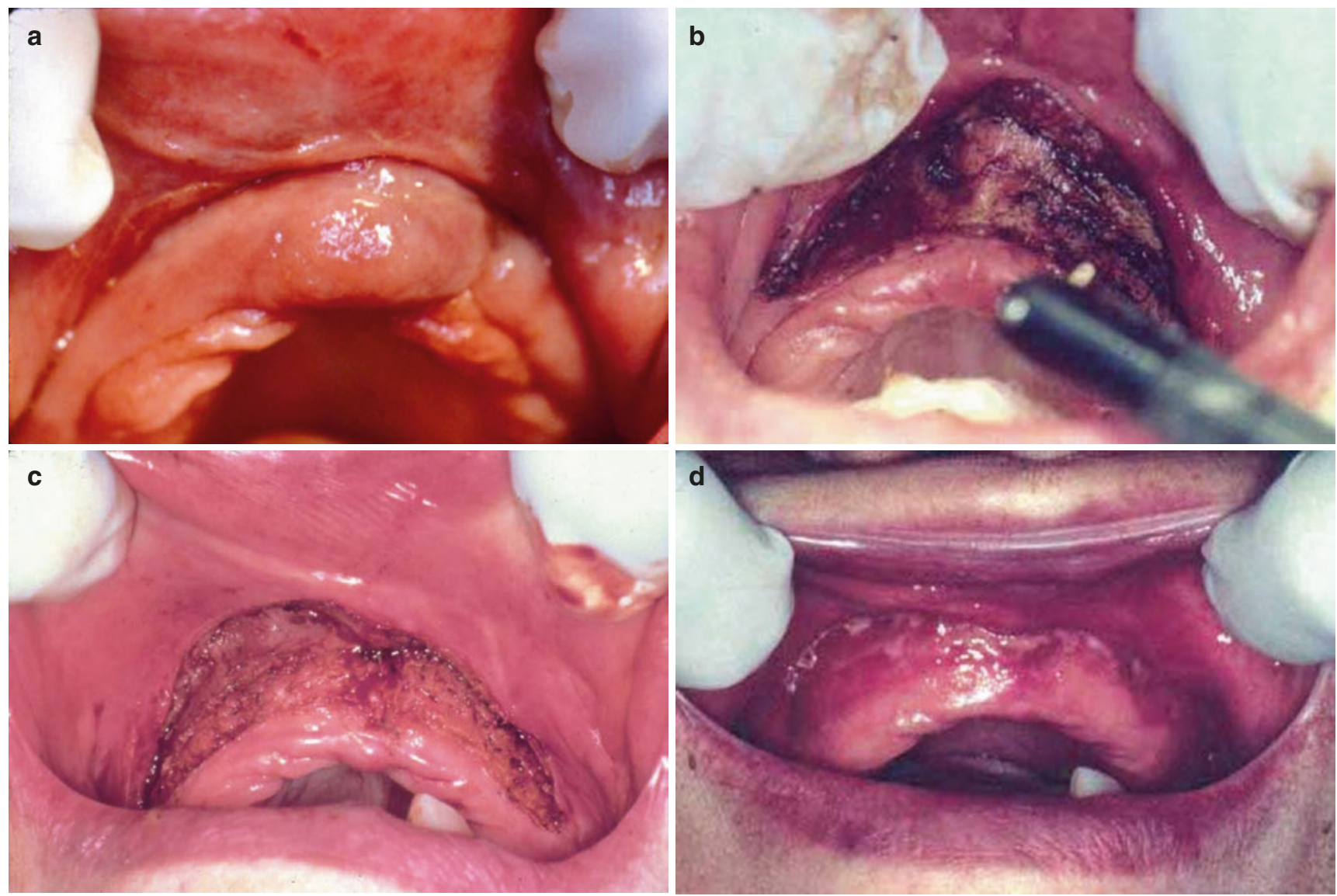

CAssociation of Oral and Maxillofacial Surgeons of India

Fig. 39.14 (a) Epulis fissuratum of maxilla. (b) Excision of epulis with $\mathrm{CO}_{2}$ laser. (c, d) Supraperiosteal dissection allowed to secondary heal 

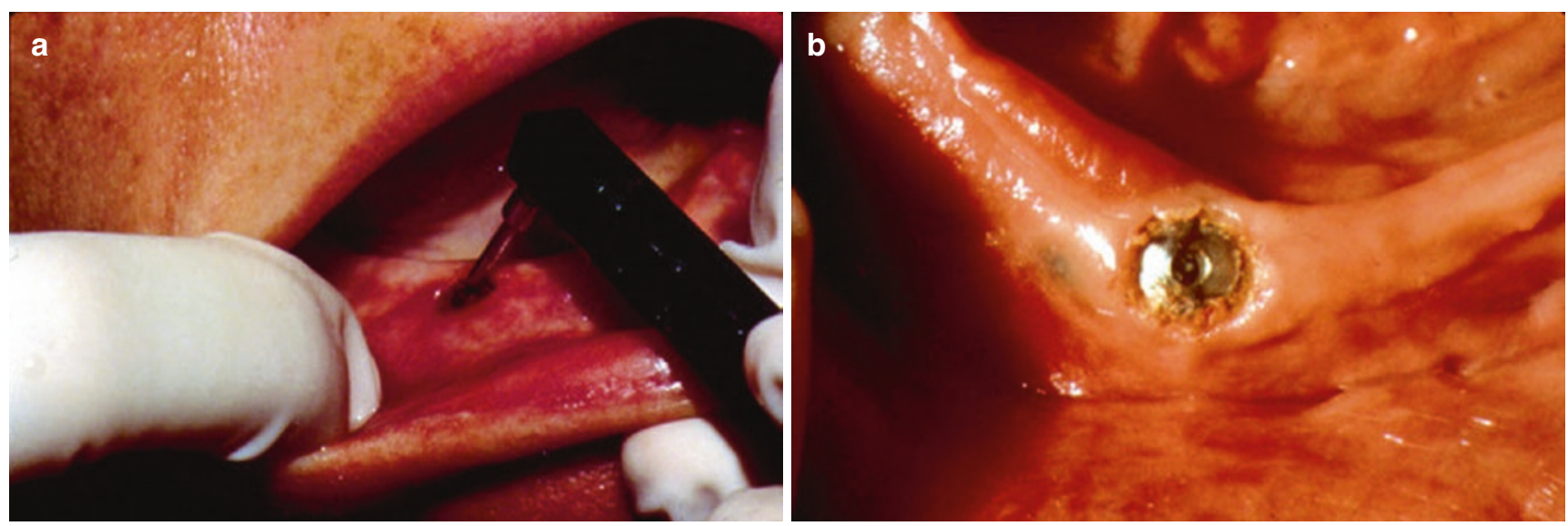

CAssociation of Oral and Maxillofacial Surgeons of India

Fig. 39.15 (a, b) Implant uncovering with $\mathrm{CO}_{2}$ laser

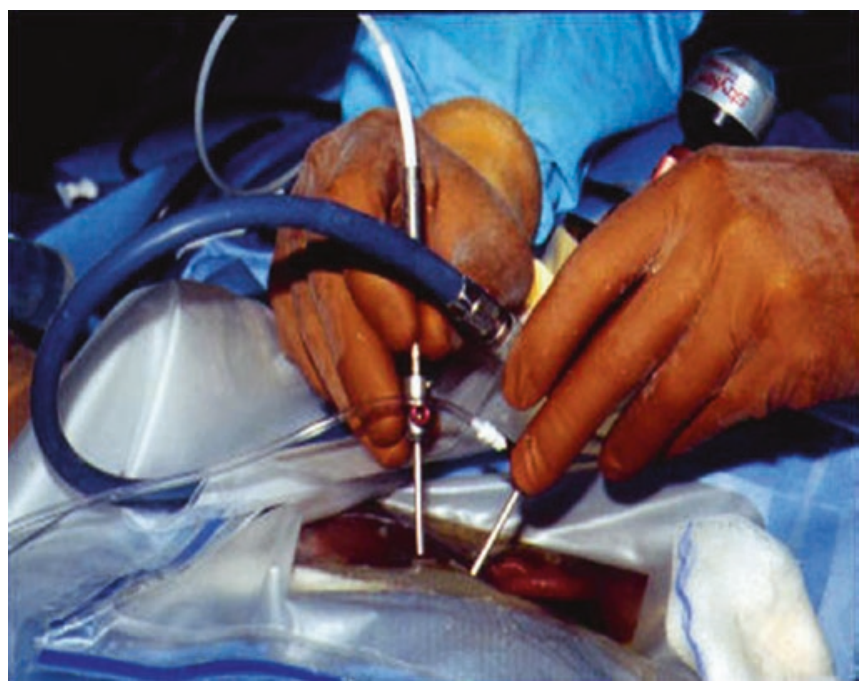

(C)Association of Oral and Maxillofacial Surgeons of India

Fig. 39.16 TMJ arthoscopy with Holmium YAG laser

\section{Temporomandibular joint surgery (TMJ):}

Arthroscopic TMJ surgeries have been proven to be efficacious, minimally invasive, and efficient procedures to treat and manage several aspects of temporomandibular joint disorders. Arthroscopic surgery utilizes various modified cutting instruments, which are passed through a narrow trocar to be able to release the disc attachments, remove redundant inflamed tissues, and/or perform synovial biopsies. These conventional cutting tools are difficult to maneuver, increase the risk of bleeding, which creates a poor visual field and a higher risk of complications. Use of lasers administered via narrowdiameter fiberoptic cables adds advantages in maneuverability, which makes it easier to sweep through the small-sized TMJ and make precise incisions and ablation with better hemostasis in a noncontact mode. Due to their high water absorption, $\mathrm{CO}_{2}$ and Er:YAG lasers cannot be used for this purpose. Ho:YAG is the commonly used laser for the purpose of TMJ arthroscopy. With low water absorption, it is less affected by the presence of the synovial and lavage fluids, while low penetration $(\sim 0.5 \mathrm{~mm})$ decreases the risk of damage to adjacent tissues. Other TMJ procedures such as disk repositioning and removal have been described with the use of arthroscopic techniques and laser assistance with significant success (Fig. 39.16) [17, 18].

\subsection{Safety Concerns with Use of Lasers}

Efficient and safe use of lasers starts with operator's familiarity with details of the laser system in use. All laser systems come with a user's manual, which lists all required technical details as well as recommended indications for use of that laser system. Common safety issues with lasers happen with accidental exposure of surrounding tissues.

\section{Personnel protection:}

Patients, providers, and the assistants are all at risk of inadvertent irradiation with lasers. Any reflective surface in the area of laser target can divert the beam away from the intended area and potentially cause harm. Use of special protective glasses (that are matched to the specific wavelength of the laser) can help avoid injury to eyes of patients or personnel in the operatory. Everyone in the operatory should be familiar with the basic functioning of the laser equipment and nonreflective tools should be used and reflective surfaces intraorally such as crowns be protected with a wet sponge or nonreflective retractors. Posting a "danger" sign for use of laser on the door of the operatory in order to avoid unprotected personnel from entering the room, while laser is in use could avoid accidental injuries as well (Fig. 39.17a, b) [6] . 

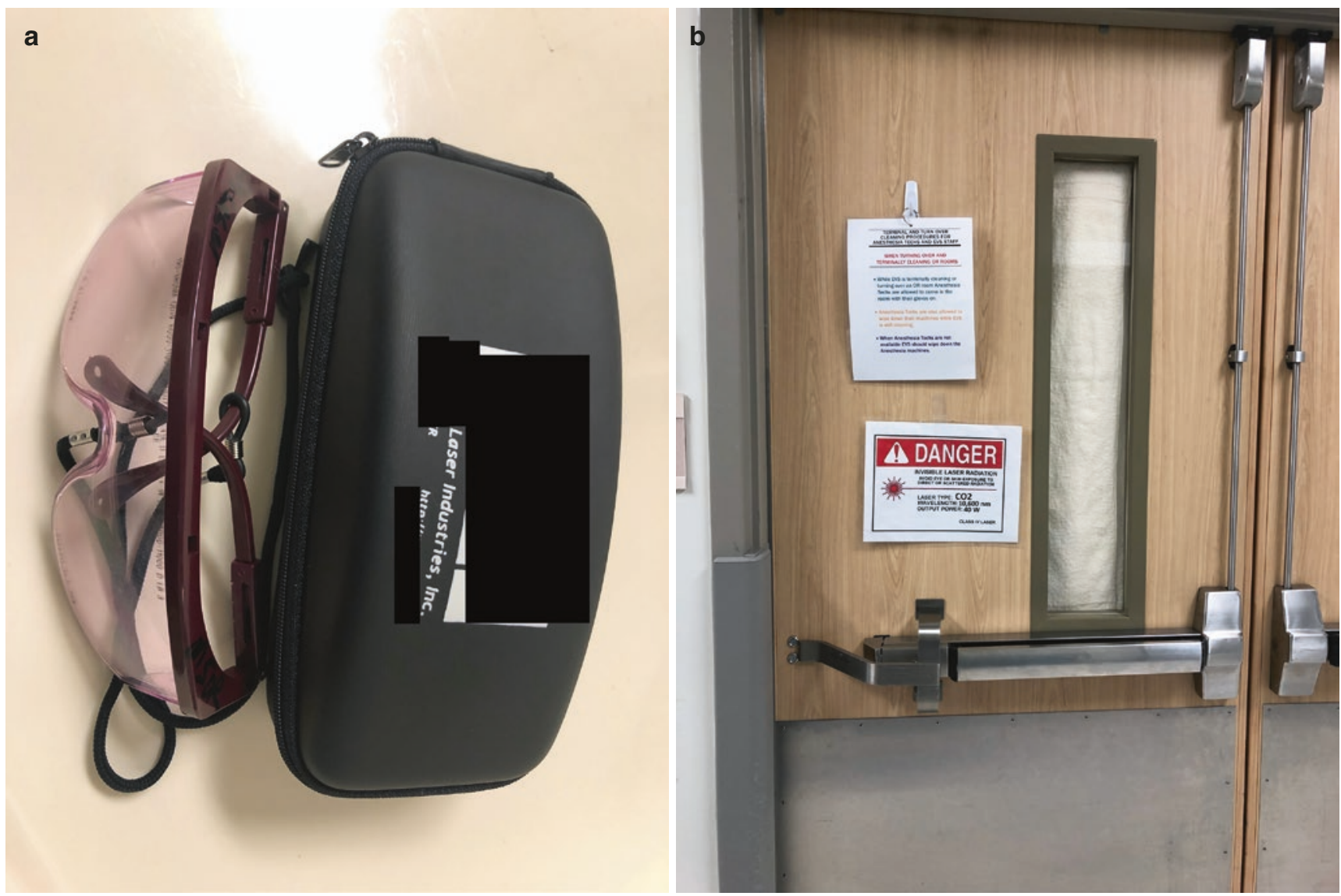

CAssociation of Oral and Maxillofacial Surgeons of India

Fig. 39.17 (a) Wavelength-specific eyewear for protection of operator, patient, and assistants. (b) "Danger" sign outside the operatory along with closure of any see-through glass panels on the door

\section{Fire hazard:}

Lasers in an oxygen-rich environmental such as the oral cavity of a patient being provided supplemental oxygen, or inside an endotracheal tube, can pose a significant fire risk. To avoid fire, supplemental $\mathrm{O}_{2}$ concentration should be kept to a minimum required level or use of room air is recommended. For endotracheal tubes, compressed air can be substituted for oxygen to keep the inspired concentrations of oxygen to below $30 \%$ [6].

\section{Laser plume:}

When a laser is used for incision or vaporization procedures, the tissue that is being handled will create a "plume," which consists of potentially hazardous particulate debris, which is considered infectious. There are studies, which showed the presence of viral DNA in the plume, but to date there hasn't been any clinical significance or transmission proven. Nevertheless, for protection of the provider/staff, high flow suction made of a nonreflective material such as plastic should be used to remove the plume. Wearing masks and other personal protective barriers such as eyeglasses will help avoid infection transmission as well [27-29].

\subsection{Conclusion}

Lasers have changed the OMS practice significantly to a point that it is today an essential surgical tool in many ways. Development of lasers in future may overcome current disadvantages and increase utility and safety. Use of lasers in hard tissue is still somewhat limited in comparison to softtissue applications. Further research and development could help improve this aspect of laser.DisclosureAuthors have no financial conflicts to disclose.

\section{References}

1. Hecht J. Beam the race to make the laser. Oxford: Oxford University Press; 2005.

2. Maiman T. Comments on his precocious five-year-old [editorial]. Laser Focus. 1965;1:2-4.

3. Sulewski JG. Einstein's "Splendid Light": origins and dental applications. In: Convissar R, editor. Principles and practice of laser dentistry. 2nd ed: Elsevier Health Sciences; 2016. p. 1-11.

4. Coluzzi DJ, Convissar RA, Roshkind DM. Laser fundamentals. In: Convissar R, editor. Principles and practice of laser dentistry. 2nd ed: Elsevier Health Sciences; 2016. p. 12-26. 
5. Strauss RA, Fallon SD. Lasers in contemporary oral and maxillofacial surgery. Dent Clin N Am. 2004;48(4):861-88.

6. Strauss RA, Coleman M. Lasers in major oral and maxillofacial surgery. In: Convissar R, editor. Principles and practice of laser dentistry. 2nd ed: Elsevier Health Sciences; 2016. p. 234-50.

7. Barak S, Kaplan I, Rosenblum I. The use of the CO2 laser in oral and maxillofacial surgery. J Clin Laser Med Surg. 1990;10:69-70.

8. Bradley P. A review of the use of the neodymium YAG laser in oral and maxillofacial surgery. $\mathrm{Br} \mathrm{J}$ Oral Maxillofac Surg. 1997;35(1):26-35.

9. Romanos G. Clinical applications of the Nd:YAG laser in oral soft tissue surgery and periodontology. J Clin Laser Med Surg. 1994;12:103-8.

10. White J, Goodis H, Rose C. Use of the pulsed Nd:YAG laser for intraoral soft tissue surgery. Lasers Surg Med. 1991;11:455-61.

11. Khatri KA, Ross V, Grevelink JM, Magro CM, Anderson RR. Comparison of erbium:YAG and carbon dioxide lasers in resurfacing of facial rhytides. Arch Dermatol. 1999;135:391-7.

12. Li Z, Reinisch L, Van de Merwe W. Bone ablation with Er:YAG and CO2 laser: study of thermal and acoustic effects. Lasers Surg Med. 1992;12:79-85.

13. Arnabat-Dominguez J, Espana-Tost AJ, Berini-Aytes L, GayEscoda C. Erbium:YAGlaser application in the second phase of implant surgery: a pilot study in 20 patients. Int J Oral Maxillofac Implants. 2003;18:104-12.

14. El-Montaser M, Devlin H, Dickinson MR, Sloam P, Lloyd RE. Osseointegration of titanium metal implants in erbium-YAG laser-prepared bone. Implant Dent. 1999;8:79-85.

15. Walsh L. The use of lasers in implantology: an overview. J Oral Implantol. 1992;18:335-40.

16. Kreisler M, Kohnen W, Marinello C, Gote H, Duschner H, Jansen B, dHoedt B. Bactericidal effect of the Er:YAG laser on dental implant surfaces: an in vitro study. J Periodontol. 2002;73:1292-7.

17. Hendler BH, Gateno J, Mooar P, Sherk HH. Holmium:YAG laser arthroscopy of the temporomandibular joint. J Oral Maxillofac Surg. 1992;50:931-4.
18. Koslin M. Laser applications in temporomandibular joint arthroscopic surgery. Oral Maxillofac Surg Clin N Am. 2004;16(2):269-75.

19. Romanos G, Nentwig G. Diode laser $(980 \mathrm{~nm})$ in oral and maxillofacial surgical procedures: clinical observations based on clinical applications. J Clin Laser Med Surg. 1999;17:193-7.

20. Mitchell O, Blackhall K, Lister T, Downie I. The use and application of lasers in oral and maxillofacial surgery. Br J Oral Maxillofac Surg. 2017;55(10):E155.

21. Guttenberg SA, Emery RW III. Laser physics and tissue interaction. Oral Maxillofac Surg Clin N Am. 2004;16(2):143-7.

22. Watson SW, Sawisch TJ. Cosmetic ablative skin resurfacing. Oral Maxillofac Surg Clin N Am. 2004;16(2):215-30.

23. Boyden DK. A brief overview of noninvasive lasers in cosmetic maxillofacial surgery. Oral Maxillofac Surg Clin N Am. 2004;16(2):231-7.

24. Wlodawsky RN, Strauss RA. Intraoral laser surgery. Oral Maxillofac Surg Clin N Am. 2004;16(2):149-63.

25. Stephen Brandon M, Strauss RA. Complications of CO2 laser procedures in oral and maxillofacial surgery. Oral Maxillofac Surg Clin N Am. 2004;16(2):289-99.

26. Julian J. Lasers in implant dentistry. In: Convissar R, editor. Principles and practice of laser dentistry. 2nd ed: Elsevier Health Sciences; 2016. p. 107-30.

27. Bellina JH, Stjernholm RL, Kurpel JE. Analysis of plume emissions after papovavirus irradiation with the carbon dioxide laser. J Reprod Med. 1982;27:268-70.

28. Mullarky MB, Norris CW, Goldberg ID. The efficacy of the CO2 laser in the sterilization of skin seeded with bacteria: survival at the skin surface and in the plume emission. Laryngoscope. 1985;95:186-7.

29. Walker NPJ, Matthews J, Newson SWB. Possible hazards from irradiation with the carbon dioxide laser. Lasers Surg Med. 1986;6:84-6.

Open Access This chapter is licensed under the terms of the Creative Commons Attribution 4.0 International License (http://creativecommons. org/licenses/by/4.0/), which permits use, sharing, adaptation, distribution and reproduction in any medium or format, as long as you give appropriate credit to the original author(s) and the source, provide a link to the Creative Commons license and indicate if changes were made.

The images or other third party material in this chapter are included in the chapter's Creative Commons license, unless indicated otherwise in a credit line to the material. If material is not included in the chapter's Creative Commons license and your intended use is not permitted by statutory regulation or exceeds the permitted use, you will need to obtain permission directly from the copyright holder. 